\title{
The evolutionary significance of pretend play: Two-year-olds' interpretation of behavioral cues
}

\author{
Lili $\mathrm{Ma}^{1} \cdot$ Angeline S. Lillard $^{2}$ (D)
}

Published online: 13 July 2017

(C) Psychonomic Society, Inc. 2017

\begin{abstract}
Pretend play begins very early in human life. A key question is why, when figuring out reality is young children's major developmental task, they engage in its deliberate falsification. A second key question is how children know that pretend events are not real. Here we report three experiments addressing the latter question and providing indirect evidence for speculation on the first question. Children $(N=96)$ were shown actors eating or pretending to eat from covered bowls, and they had to indicate, on the basis of the actors' behavioral signs, which actor was pretending to eat or had the real food. Even 24-month-olds could do so when the contents of the bowls were shown before the actions, and even when substitute objects were shown. However, when one of the bowls contained imaginary objects (i.e., was empty), even 30month-olds could not indicate which actor was pretending. These studies show how the ability to interpret pretending from behavioral cues develops gradually as children's representational abilities become more free of contextual support. We propose that, from an evolutionary and ontogenetic standpoint, pretend play might serve to heighten children's sensitivity to social signs. This sensitivity could assist the development of theory of mind, with which social pretend play is associated. In this way, pretend play in humans might serve a similar purpose to play fighting in other species: In both cases, play might sensitize the organism to social signs that will allow for sophisticated coordination of social behavior later in life.
\end{abstract}

Angeline S. Lillard

lillard@virginia.edu

1 Department of Psychology, Ryerson University, Toronto, Ontario, Canada

2 University of Virginia, Charlottesville, VA, USA
Keywords Play · Symbolic representation · Behavioral cues · Social sensitizer $\cdot$ Children

In pretend play, one reality is stretched over another for the purpose of fun and amusement (Lillard, 2015). For example, children might employ blocks for a "tea party," projecting their mental representations of a cup and saucer, food and tea onto the blocks, and thus acting out a tea party scenario. The flexibility and ubiquity of such behaviors in early childhood are uniquely human (see Mitchell, 2002). Children in all cultures pretend, going through specific developmental stages (Gaskins, 2013; Göncü, Mistry, \& Mosier, 2000; Lancy, 2007; Piaget, 1962). In addition, pretend play constitutes a significant percentage of young children's waking hours, at least in middle-class American homes (Haight \& Miller, 1993). Such play also starts quite young: early in the second year, which has been observed in both natural and experimental settings (e.g., Bretherton et al., 1981; Haight \& Miller, 1993; Watson $\&$ Fischer, 1977). Furthermore, children seem to understand pretending in others as soon as they begin to pretend themselves. Hence, Leslie (1987) claimed that a young child who sees his or her mother talk into a banana automatically processes the behavior as the mother pretending that the banana is a telephone; he claimed that this processing is not learned, but is an innate social-cognitive capacity. Parents pretend in front of very young children (Haight \& Miller, 1992; Slade, 1987) - even 7-months-olds, in one study (Kavanaugh, Whittington, \& Cerbone, 1983). To avoid being confused by these pretend displays, young children must read them as pretend (Leslie, 1987; Piaget, 1962). If children were not able to process such events correctly, this would lead to deep confusion about the real world.

Researchers have asked why, at the very ages when children are developing basic representations of the world, they engage 
in an activity that misrepresents reality (Buchsbaum, Bridgers, Weisberg, \& Gopnik, 2012; Leslie, 1987)? After all, the primary task of early childhood is figuring out how the real world works. One possible reason is because pretend play might offer benefits for children. One potential benefit is to sensitize children to social signs, such as facial expressions and behavioral tempo. As such, it might help develop capacities that are of broad application, like a capacity to read social signs, which could then support the development of a theory of mind.

Research on play in animals clearly supports the idea that play fighting involves reading social signals and is key for later social behavior (Pellis, Burghardt, Palagi, \& Mangel, 2015). Play fighting is a common activity, particularly in mammals, and can be seen as analogous to ritualized pretend play-ritualized because there are precise ways that play fighting is enacted (e.g., Bekoff, 1995; Fagen, 1981; Pellis \& Pellis, 2009, 2016), unlike children's pretend play, which is relatively unconstrained. Play fighting is pretend-like because it involves actions that symbolize other actions. Bateson (1972, p. 317) famously noted that in play fighting, animals must understand that "the playful nip is not the bite," although it denotes the bite. Play fighting also involves metacommunication. Animals signal to each other that they are play (rather than actually) fighting - signals like the play bow of canids (Bekoff, 1995), and among rats a special location for "bites" (Pellis \& Pellis, 2016) and a high-pitched chirp (Knutson, Burgdorf, \& Panksepp, 1998). Animals that are deprived of play fighting in the juvenile period have social deficits later (Pellis et al., 2015).

Human adults also appear to produce behavioral cues to signal pretense to young children. Empirical research has demonstrated that, in both Western and Eastern cultures, mothers alter their behaviors in predictable ways when pretending, relative to when they engage in the same activities for real (Hoicka \& Butcher, 2015; Lillard et al., 2007; Lillard \& Witherington, 2004; Nakamichi, 2015). For example, when asked to pretend to eat in front of their toddlers, mothers moved faster, produced sound effects, engaged in exaggerated smiles, and had more variations in pitch when speaking. Moreover, they engaged in a "social referencing sequence," in which they locked eyes with their child, engaged in the pretend behavior, and then smiled (as if to comment, "Take this as silly"). Toddlers whose mothers engaged in these behaviors seemed to understand the behaviors as pretend more than did toddlers whose mothers did not, as indicated by the toddlers smiling and engaging in pretend behaviors themselves (Nishida \& Lillard, 2007). These behaviors are also predictive of development: 18-month-olds whose mothers emitted more cues while pretending better understood another person's pretense 6 months later, when they were 24 months old (Nakamichi, 2015). This suggests that early social pretense could assist the development of at least one aspect of theory of mind: understanding that others are pretending.
However, the above-mentioned studies were limited to mother-child dyads. Understanding an unfamiliar person's pretending might be more difficult. Ma and Lillard (2006) used a more stringent test, with a stranger emitting the behavioral signs of pretense. In their study, children watched four video clips in which one person was really eating food from a bowl, and another person was pretending to eat from a different bowl, using the signs revealed in the earlier studies. Both containers were covered, and the hands were held such that content information was not available as a cue. At the end of the video clip, the two covered bowls from the video were brought out from behind the television screen, and children were asked to indicate where the real food was. Thirty-montholds succeeded in choosing the correct bowl more often than would be expected by chance. Two-year-olds' spontaneous behaviors differed in response to the real versus pretend acts (e.g., they smacked their lips and reached more toward real than toward pretend ones), suggesting that they were able to detect the real-pretend distinction at an implicit level, but they failed the explicit task of indicating which bowl had real food.

Building on these findings, the purpose of the present study was twofold. First, in Ma and Lillard (2006), to correctly indicate where the real food was, children had not only to distinguish between real and pretend acts, but also to reason that a person engaging in real behavior is more likely to use real objects than is a pretender. The demand for making the second inference might have hindered the performance of the 2-yearolds. If the child is provided with more explicit information about only one container having the real food, this reasoning demand might be reduced, which could lead to enhanced performance. Experiment 1 was conducted to test this possibility with 2-year-olds, by showing the child the contents inside the two bowls to be used prior to the pretend and real eating events. The reason that we examined children of 24 and 30 months (in all three experiments) is because the ability to read pretense in unfamiliar others - as indicated by explicit behaviors-appears to emerge across this period (Harris \& Kavanaugh, 1993; Ma \& Lillard, 2006).

H1: Adding perceptual information that one bowl is empty and another has real food to the signs of pretense will support even 2-year-olds' ability to distinguish pretend and real acts (Exp. 1).

Second, a more definite understanding of the real-pretend distinction goes beyond the recognition that a person engaging in real behavior is more likely to have real objects than is a pretender. The observer must also infer that a pretender may sometimes use substitute or imaginary objects to anchor his or her pretense. Experiments 2 and 3 were conducted to examine whether 2-year-olds were able to make this inference, first with substitute objects and then with imaginary objects (i.e., pantomime). Thus, we tested two more hypotheses: 
H2: Adding perceptual information that one bowl has substitute objects and another has real food to the signs of pretense will support even 2-year-olds' ability to indicate a pretend act (Exp. 2).

H3: Adding perceptual information that one bowl is empty and another has real food to the signs of pretense will support even 2-year-olds' ability to indicate a pretend act (Exp. 3).

In all three experiments, although children saw the contents of the stimulus bowls ahead of time, pretense was signaled in situ by behavioral cues alone, in the absence of content information. No child participated in more than one experiment.

\section{Experiment 1}

\section{Method}

\section{Participants}

The sample included 32 children, sixteen 24-month-olds $(M=$ 24.8 months, range $=23.4-26.9$ months; eight girls $)$ and sixteen 30-month-olds $(M=30.3$ months, range $=29.3-32.0$ months; eight girls). Six more children were recruited but were eliminated from the final sample because of fussiness (two), failure to pass the pretest (two), shyness (one), or sibling interference (one). The sample size here and in the subsequent two experiments was chosen on the basis of prior studies, which had obtained significant effects with similar group sizes. ${ }^{1}$ The children (in all the experiments reported here) were recruited in a small mid-Atlantic American city, through a participant database maintained by a group of developmental psychologists at a public university. The majority of the children came from White middle-class families, consistent with the population from which they were drawn.

\section{Materials and stimuli}

The stimuli included five video clips (described below) of paired events on a split screen. One clip was used for the pretest, and four clips were used for test trials. Two containers were used with each clip: two boxes for the pretest (one yellow and one red) and two small plastic bowls, each with differently colored cloth covers for each test trial. In addition, a toy animal was used for the pretest, and four kinds of snacks (grape halves, cheese cubes, muffin pieces, and raisins) were used for the test trials.

\footnotetext{
${ }^{1}$ A priori power analyses would be a better approach for determining sample sizes.
}

Pretest clip The main test of this study required children to map what they saw on television to the real world. To ensure that children had no difficulty with this prerequisite, we conducted a pretest using a televised video clip. Two female adults appeared in this clip, sitting next to each other on a split screen. Each adult had an opaque box in front of her on a small table. One adult lifted up a yellow box and found a toy animal. She made an excited face and then placed the box back on the table, hiding the toy under it. The other adult lifted up a red box and found nothing under it. She expressed disappointment and then placed the box back on the table.

Test clips In each of the four test clips, a different pair of female adults engaged in real versus pretend eating with a different snack in each clip (see the Materials above). At the beginning of each clip, the adults were sitting next to each other on a split screen and reading magazines. Each had a covered bowl in front of her on the same table shown in the pretest clip. Then they took turns: One adult began to eat (or pretended to eat) from the bowl in front of her. After about $30 \mathrm{~s}$ she stopped and resumed reading her magazine. Then the other adult began to pretend (or really eat) for about $30 \mathrm{~s}$ and resumed reading her magazine afterward. At the end of the clip, both adults had resumed reading the magazines. The clips lasted from 60.2 to $63.1 \mathrm{~s}$.

In each clip, the pretender produced signs of pretense that had been revealed in the research cited earlier-for example, sound effects, animated movements, holding food at the mouth for a longer-than-normal duration, and exaggerated smiles. The adult who was really eating consumed the food quietly and did not make obvious eating sounds. When eating (or pretending to eat) from the covered bowls, both adults held their hands in such a way that viewers were not able to see whether or not real food was involved. This was done to ensure that content information was not available as a cue to pretense; this was confirmed by adult viewers. In addition, in an earlier study, adults and 5-year-old children had correctly classified the clips, confirming that it was very easy to identify the pretender in each clip on the basis of the behavioral cues alone (Ma \& Lillard, 2006).

\section{Procedure}

The study took place in a small, quiet room. The child was seated in a small chair in front of a table. A 21-in. color television was placed in the middle of the table, about $50 \mathrm{~cm}$ away from the child. The parent sat next to the child and was instructed not to interfere with the procedure, although the parents did deliver the test question, because pilot research had shown that young children responded well to parent requests. A video camera recorded the child's behavior throughout the study. 
Pretest In the pretest, the child watched the video clip as described above, with the two actual boxes placed directly in front of their counterparts on the screen. At the end of the clip, the researcher paused the video, with the still images of the two adults on the screen. Then the parent looked directly at the child and asked, "Where is the toy animal? Can you point to the box with the toy animal?" For all the experiments here, parents were instructed how to deliver the test question without cueing the child through looks, weight shifting, or gestures that might indicate the correct answer. After clearly pointing to one of the boxes, the child was given the selected box and allowed to lift it. The side of the target choice (left or right) was counterbalanced across participants in each age group. One child did not pass the pretest and thus was not included in the final sample.

Test The test phase followed, with each child watching four video clips as described above, one at a time. Before each trial, the researcher showed the child the two bowls to be used, with one in front of the other, so the child could see that only one bowl had the real snacks and the other one was empty. Next, she covered the bowls out of the child's view (i.e., behind the television, so the children could not see which bowl had which color of cover) and placed them back on the table. Then the clip was played, with the two bowls directly in front of their counterparts on the screen throughout the presentation. At the end of the clip, the researcher paused and pushed the bowls to within the child's reach, with the images of the two adults still on the screen. Then the parent asked: "Where are the real [snacks]? Can you point to the bowl with the real [snacks]?" After clearly pointing to one of the bowls, the child was given the selected bowl to see what was inside. The researcher also invited the child to look inside the second bowl afterward. At the end of each trial, the child was allowed to eat the snacks as a reward, regardless of whether he or she had made the correct choice. The next trial ensued. The side of the target choice (left or right) was alternated across trials; on the first trial it was counterbalanced across participants.

\section{Coding and reliability}

For each test trial, the child's first decisive point (i.e., choice) in response to the parent's request was coded from video recordings by the first author. A trained undergraduate research assistant (RA) also coded the entire sample for reliability. The RA was aware of the study's hypothesis but was unable to see the adults or the container locations on the video recordings. The two coders agreed $98 \%$ of the time; disagreements were resolved by discussion.

\section{Results and discussion}

For each child, the proportion of trials (out of four) on which he or she made the correct choice (i.e., pointing to the bowl with real snacks) was calculated (see Fig. 1). This proportion score was submitted to a two-way analysis of variance (ANOVA) with age (2: 24 vs. 30 months) and gender as between-subjects factors. The results indicated that there was no significant main effect of age or gender, nor a significant interaction.

Children's correct responding (as a proportion) was then compared to chance expectation (.50), using one-sample $t$ tests. Although the lack of age differences in the ANOVA would justify combining the age groups, we kept the groups separate in order to more conservatively test whether children's performance differed from chance. When asked to point to the bowl with real snacks, 30-month-olds made the correct choice significantly more often than would be expected by chance $(M=.70, S D=.245), t(15)=3.31, p=.005$, Cohen's $d=0.82$, as did 24-month-olds $(M=.67, S D=.218)$, $t(15)=3.15, p=.007$, Cohen's $d=0.78$ (see Fig. 1; Lakens, 2013). Wilcoxon signed-rank tests confirmed this result (30month-olds, $p=.010$; 24-month-olds, $p=.013$ ).

Thus, supporting H1, when it was clear that only one person had real food, even 24-month-olds were able to discriminate real acts from pretense on the basis of behavioral signs alone. However, in this experiment, as in $\mathrm{Ma}$ and Lillard (2006), children were asked where the real food was. It is possible that children might have read the real behavior as real, rather than the pretend behavior as pretend. To examine this possibility, Experiment 2 directly tested whether 2-yearolds are able to read pretend behavior as pretend (H2). In particular, can they infer that a pretender uses substitute objects to anchor his or her pretense? Before each test trial, the researcher showed the contents of the two bowls, revealing to children that one bowl had real food and the other bowl had small toys. The subsequent procedure was the same as that of Experiment 1. At the end of the clip, children were asked to indicate which bowl had the small toys (i.e., substitute objects).

\section{Experiment 2}

\section{Method}

Participants The sample was a new 32 children, sixteen 24month-olds $(M=24.5$ months, range $=22.6-26.2$ months; eight girls) and sixteen 30-month-olds ( $M=30.6$ months, range $=29.2-33.2$ months; eight girls). Nine additional children were excluded from the final sample because of fussiness or inattentiveness (four), failure to pass the pretest (two), parent interference (two), or shyness (one). 
Mean Proportion of Correct Choice

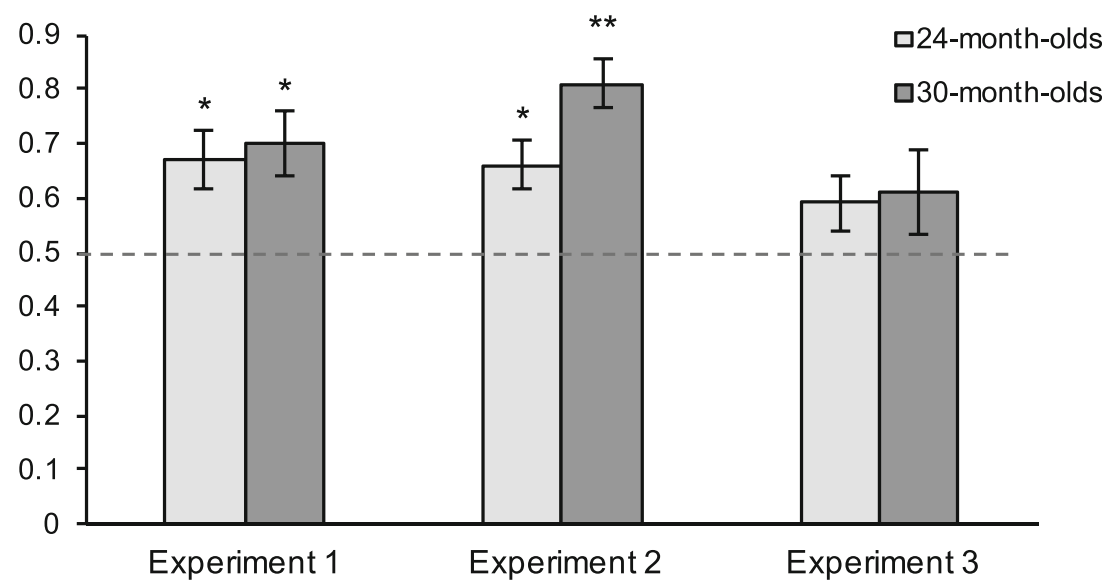

Fig. 1 Mean proportions of correct choices by experiment and age. ${ }^{*} p<.01,{ }^{* * *} p<.001$, as compared to chance expectation $(.50)$. Bars represent standard errors

Materials, stimuli, procedure, and coding The same materials and stimuli from Experiment 1 were used, with the addition of 16 mini toys (four for each test trial). The procedure was the same as in Experiment 1, except for the following two changes during the test: (a) before each test trial, the researcher showed the two bowls to be used, so the child could see that one bowl had real snacks and the other one had small toys, and (b) at the end of each clip, the parent asked the child to point to the bowl with small toys: "Where are the toys? Can you point to the bowl with the toys?" As in Experiment 1, the hands were cupped so that the child could not see whether or not the actor held toys or food during the presentation, and the child's first point in response to the parent's question was coded. At the end of each trial, the child was allowed to eat the snacks as a reward.

\section{Results and discussion}

For each child, the proportion of trials (out of four) on which the child made the correct choice (i.e., pointing to the bowl with small toys) was calculated (see Fig. 1). A two-way ANOVA with age and gender as between-subjects factors revealed a significant main effect of age, $F(1,28)=6.14, p=$ $.02, \eta_{\mathrm{p}}{ }^{2}=.18$, with 30 -month-olds $(M=.81, S D=.171)$ outperforming 24-month-olds $(M=.66, S D=.180)$. The main effect of gender and the interaction between age and gender were not significant.

Children's correct responding was then compared to chance performance $(.50)$. When asked to point to the bowl with small toys, both the 30- and 24-month-olds made the correct choice significantly more often than would be expected by chance, $t(15)=7.32, p<.001$, Cohen's $d=1.81$, and $t(15)=3.48, p=.003$, Cohen's $d=0.89$, respectively (onesample $t$ tests; see Fig. 1). Wilcoxon signed-rank tests indicated consistent results (30-month-olds, $p=.001 ; 24$ month-olds, $p=.008$ ). Thus, although 30-month-olds did better than 24-month-olds at interpreting a pretend event involving substitute objects, even 24-month-olds were above chance at doing so, when it was made clear prior to the pretend event that one actor had real food and the other had pretend substitute objects. H2 was thus supported.

Research has indicated that children begin to engage in object-substitution pretense at around 24 months of age- - for example, calling a ball an apple and pretending to eat it (e.g., Jackowitz \& Watson, 1980; Pederson, Rook-Green, \& Elder, 1981; Watson \& Jackowitz, 1984). The results of Experiment 2 suggest that, at around the same time, children are also able to read another person's object-substitution pretense as pretend on the basis of behavioral signs alone. After watching displays of real versus pretend eating behavior in the absence of content cues, both 24- and 30-month-olds correctly inferred that the pretender, not the person acting for real, had the substitute objects. A further question concerned whether this ability extends to understanding another person's pretense that involves imaginary objects - a later development in children's own pretense than using pretend substitute objects. Experiment 3 was conducted to address this question.

\section{Experiment 3}

\section{Method}

Participants The participants were 32 children, sixteen 24month-olds $(M=24.4$ months, range $=23.0-26.9$ months; eight girls) and sixteen 30-month-olds ( $M=30.5$ months, range $=29.2-32.7$ months; eight girls). One additional child failed the pretest and thus was excluded from the final sample. 
Materials, stimuli, procedure, and coding The same materials and stimuli were used as in Experiment 1. The procedure was the same as in Experiment 1, except that at the end of each clip, the parent asked the child to point to the bowl that was empty: "Which bowl is empty and has nothing in it? Can you point to the bowl that has nothing in it?" At the end of each test trial, the child was rewarded with the snacks. For each trial, the child's first point in response to the parent's request was coded.

\section{Results and discussion}

As in the previous two experiments, for each child the proportion of trials on which he or she made the correct choice (i.e., pointing to the empty bowl) was calculated (see Fig. 1). A two-way ANOVA with age and gender as between-subjects factors indicated no significant main effect of age or gender, nor a significant interaction.

One-sample $t$ tests showed that when asked to point to the bowl that was empty, neither age group made the correct choice more than would be expected by chance (30-montholds: $M=.61, S D=.30 ; 24$-month-olds: $M=.59, S D=.20$ ), $t(15)=1.45, p=.17$, and $t(15)=1.86, p=.08$, respectively (see Fig. 1). Thus, when a pretense involved imaginary objects, 2-year-olds were unable to indicate which actor had no food. The child's pretense representation —of pretending being indicated by behavioral cues and of nonexistent food-is as yet still too fragile to support a correct response in this scenario. H3 was not supported.

\section{General discussion}

In three experiments, we sought to examine whether 2-yearolds could read behavioral signs of pretense and make the real-pretend distinction in the absence of direct perceptual information indicating whether real objects were involved. Children ages 2 and 2.5 years watched real versus pretend eating behavior and were tested on whether they could associate real food with a person acting for real or associate substitute and imaginary food with a person emitting the signs of pretense. Three main findings emerged and will be discussed in turn.

The first finding concerns 2-year-olds' performance in comparison to that of the 2-year-olds in $\mathrm{Ma}$ and Lillard (2006). In the present study, with prior knowledge that only one container had real food and that the other container was empty, even 24-month-olds made sense of the behavioral cues to pretense and understood that the person acting for real was more likely to have real food than was the pretender (Exp. 1). In Ma and Lillard (2006), whereas 30-month-olds correctly associated real food with the person acting for real, 24month-olds did not. The enhanced performance of the 24 - month-olds in the present study may be attributed to the reduced task demands in the face of increased contextual support. In the prior research, when asked to indicate where the real food was, children had to not only make the real-pretend distinction based on behavioral cues, but also reason about what might be in the bowls. Removing this second task demand, by showing children ahead of time that only one container had real food and the other one was empty, led to better performance: Even the 24-month-olds correctly associated real food with the person acting for real rather than the pretender. Hence, when real objects are involved and children know what objects are really present, by age 2 they can read the signs of pretense even when the signs are emitted by a stranger.

The second finding regards 2-year-olds' ability to read object-substitution pretense based on behavioral cues alone. After seeing that one container had real food and the other container had small toys, both 30- and 24-month-olds were able to make correct inferences based on the behavioral signs of pretense. Thirty-month-olds performed better than 24month-olds, but even 24-month-olds realized that the pretender was the one with the substitute objects (i.e., the small toys). This finding is an important extension of previous work, because it indicates that by 24 months, children can not only interpret real behavior as real but can also read pretend behavior as pretend on the basis of behavioral cues alone, an ability previously not observed in such young children (Ma \& Lillard, 2013; Richert \& Lillard, 2004).

The third finding reveals that 2-year-olds' ability to understand pretense based on behavioral cues might be limited in some pretend scenarios. In Experiment 3, when asked to indicate which container was empty (as opposed to which had real food), both 30- and 24-month-olds responded at random, failing to associate imaginary food with the pretender. Their poor performance might reveal the fragility of their representation of the situation. To elaborate, in the development of objectsubstitution pretense, children become less dependent on realistic objects or replicas as they become more adept at understanding and using symbolic representations (Elder \& Pederson, 1978). At 24 months, most children still anchor their make-believe activities with support from realistic toy replicas, but in the next year they begin to pretend well with substitute objects that are dissimilar to the referents. Between 2 and 3 years of age, children also begin to use their body parts in object-substitute pretense - for example, pretending that a finger is a tooth brush. The ability to pretend with imaginary objects emerges between 3 and 5 years old (e.g., Elder \& Pederson, 1978; Mitchell \& Clark, 2015). This developmental trend points to the possibility that, before 3 years of age, the strength of children's representations of pretense is likely challenged by imaginary objects; imaginary objects have no perceptual supports, and thus require a stronger mental representation. In Experiment 3, children had to decipher the pretend 
scenario on the basis of behavioral signs and hold in mind a representation of real food with no perceptual support. When asked to indicate which bowl was empty, they were unable to evoke that representation. As a result, they were unable to associate the imaginary objects with the pretender rather than the person acting for real. However, we do note that at $60 \%$ correct, the results might indicate that this ability is emerging early in the third year of life.

These studies show an emerging ability to read pretend events on the basis of behavioral signs of pretense in conjunction with limited knowledge of reality - in this case, knowing ahead of time which bowl had real food and which had toys or was empty. Two-year-olds could indicate which person was really eating (Exp. 1) and which was pretending to eat small toy substitute objects (Exp. 2), but they could not yet indicate which person was eating purely imaginary food.

Using behavioral signs of pretense requires acute sensitivity to social displays. Many have asked what purpose pretend play might serve. We speculate that one possibility is to hone social sensitivities, first allowing children to interpret pretend behavior and then to apply those skills more broadly, to better interpret other communicative gestures as well.

As support for this conjecture, note that more frequent social or role play is associated with more advanced theory of mind (Astington \& Jenkins, 1995; Youngblade \& Dunn, 1995). It is unclear whether social pretend play leads to theory of mind or whether children with better theory of mind are more able to engage others in social pretend play (see Dore, Smith, \& Lillard, 2015); we suspect the relation might go both ways. Furthermore, Japanese toddlers whose mothers produce more signs of pretense when pretending later show advanced understanding of a stranger's pretend actions (Nakamichi, 2015). Because this research in Japan replicated and extended our original findings, we expect that our basic claims apply universally, but further research in different cultural settings would give them a stronger basis. In sum, we find it conceivable that the evolutionary and ontogenetic significance of pretend play in humans is to sensitize them to social signs, supporting the development of theory of mind.

Although pretend play is uniquely human in its flexibility, both humans and nonhuman animals engage in a particular activity that could be seen as pretend-play-like: play fighting (Boulton, 1996; Pellis \& Pellis, 2007). In animals this activity is stereotyped - for example, there are particular locations at which a play-fighting rat "bites" another rat, and these are different from where bites are placed when really fighting (Pellis \& Pellis, 2009). However, the fact of "play" signaling is similar across human and animal play, and it might serve a similar function. As Bateson (1972) pointed out, play fighting animals need to read social signs, in order to avoid really fighting when play fighting. As we noted earlier, dogs issue (and interpret) a play bow (Bekoff, 1995) and rats emit a highpitched noise (Knutson et al., 1998) as metacommunicative signs of play fighting. Adult animals that are deprived specifically of the opportunity to play when young (yet are not deprived of other social contact) are impaired at reading and coordinating social behaviors (Einon \& Morgan, 1977; Einon \& Potegal, 1991; see also Pellis \& Pellis, 2009). Pretend play might serve an analogous function in human children to what play fighting appears to serve in some animals, in that through becoming adept at reading pretend play signals, children might hone social perception, and thereby social skills, and even theory of mind more generally (Lillard, 2017).

In conclusion, by 24 months, children discriminate real acts from pretend acts that are marked by specific behavioral cues, even when strangers emit those signs. With advance knowledge of substitute objects, even 24-month-olds read pretend behavior as pretend, but reading pretense with imaginary objects appears to develop after 30 months of age. Behaviors that mark pretense likely evolved from signs of play fighting, but are flexibly applied to other pretend situations for humans. Learning to read such signals as a human child might serve a developmental purpose analogous to engaging in play fighting, which also involves reading and interpreting social signs and serves an important developmental purpose in other species.

\section{References}

Astington, J. W., \& Jenkins, J. M. (1995). Theory of mind development and social understanding. Cognition and Emotion, 9, 151-165. doi: 10.1080/02699939508409006

Bateson, G. A. (1972). A theory of play and fantasy. In G. A. Bateson (Ed.), Steps to an ecology of mind (pp. 177-193). New York: Chandler.

Bekoff, M. (1995). Play signals as punctuation: The structure of social play in canids. Behaviour, 132, 419-429. doi:10.1163/ 156853995X00649

Boulton, M. J. (1996). A comparison of 8- and 11-year-old girls' and boys' participation in specific types of rough-and-tumble play and aggressive fighting: Implications for functional hypotheses. Aggressive Behavior, 22, 271-287.

Bretherton, I., Bates, E., McNew, S., Shore, C., Williamson, C., \& Beeghly-Smith, M. (1981). Comprehension and production of symbols in infancy: An experimental study. Developmental Psychology, 17, 728-736. doi:10.1037/0012-1649.17.6.728

Buchsbaum, D., Bridgers, S., Weisberg, D. S., \& Gopnik, A. (2012). The power of possibility: Causal learning, counterfactual reasoning, and pretend play. Philosophical Transactions of the Royal Society B: Biological Sciences, 367, 2202-2212. doi:10.1098/rstb.2012.0122

Dore, R. A., Smith, E. D., \& Lillard, A. S. (2015). How is theory of mind useful? Perhaps to enable social pretend play. Frontiers in Cognitive Science, 6(1559), 1-4. doi:10.3389/fpsyg.2015.01559

Einon, D. F., \& Morgan, M. (1977). A critical period for social isolation in the rat. Developmental Psychobiology, 10, 123-132. doi:10.1002/ dev.420100205

Einon, D. F., \& Potegal, M. (1991). Enhanced defense in adult rats deprived of playfighting experience as juveniles. Aggressive Behavior, 
17, 27-40. doi:10.1002/1098-2337(1991)17:1<27::AIDAB2480170105>3.0.CO;2-B

Elder, J. L., \& Pederson, D. R. (1978). Preschool children's use of objects in symbolic play. Child Development, 49, 500-504. doi:10.2307/ 1128716

Fagen, R. (1981). Animal play behavior. Oxford: New York.

Gaskins, S. (2013). Pretend play as culturally constructed activity. In M. Taylor (Ed.), The Oxford handbook of the imagination (pp. 224247). New York: Oxford.

Göncü, A., Mistry, J., \& Mosier, C. (2000). Cultural variations in the play of toddlers. International Journal of Behavioral Development, 24, 321-329. doi:10.1080/01650250050118303

Haight, W., \& Miller, P. J. (1992). The development of everyday pretend play: A longitudinal study of mothers' participation. Merrill-Palmer Quarterly, 38, 331-349.

Haight, W., \& Miller, P. J. (1993). Pretending at home. Albany: SUNY Press.

Harris, P. L., \& Kavanaugh, R. D. (1993). Young children's understanding of pretense. Monographs of the Society for Research in Child Development, 58(1, Serial No. 231), 1-107.

Hoicka, E., \& Butcher, J. (2015). Parents produce explicit cues that help toddlers distinguish joking and pretending. Cognitive Science, 40, 941-971. doi:10.1111/cogs.12264

Jackowitz, E. R., \& Watson, M. W. (1980). The development of object transformations in early pretend play. Developmental Psychology, 16, 543-549. doi:10.1037/0012-1649.16.6.543

Kavanaugh, R. D., Whittington, S., \& Cerbone, M. J. (1983). Mothers' use of fantasy speech to young children. Journal of Child Language, 10, 45-55. doi:10.1017/S0305000900005122

Knutson, B., Burgdorf, J., \& Panksepp, J. (1998). Anticipation of play elicits high-frequency ultrasonic vocalizations in young rats. Journal of Comparative Psychology, 112, 65-73. doi:10.1037/ 0735-7036.112.1.65

Lakens, D. (2013). Calculating and reporting effect sizes to facilitate cumulative science: A practical primer for $t$ tests and ANOVAs. Frontiers in Psychology, 4, 863.

Lancy, D. F. (2007). Accounting for variability in mother-child play. American Anthropologist, 109, 273-284. doi:10.1525/aa.2007. 109.2.273

Leslie, A. M. (1987). Pretense and representation: The origins of "theory of mind.”. Psychological Review, 94, 412-426. doi:10.1037/0033295X.94.4.412

Lillard, A. S. (2015). The development of play. In L. S. Liben \& U. Mueller (Eds.), Handbook of child psychology and developmental science: Cognitive processes (7th ed., Vol. 2, pp. 425-468). New York: Wiley-Blackwell.

Lillard, A. S. (2017). Why do the children (pretend) play? Manuscript submitted for publication.

Lillard, A. S., Nishida, T., Massaro, D., Vaish, A., Ma, L., \& McRoberts, G. (2007). Signs of pretense across age and scenario. Infancy, 11, 130. doi:10.1080/15250000709336868

Lillard, A. S., \& Witherington, D. (2004). Mothers' behavior modifications during pretense snacks and their possible signal value for toddlers. Developmental Psychology, 40, 95-113. doi:10.1037/00121649.40.1.95
Ma, L., \& Lillard, A. S. (2006). Where is the real cheese? Young children's ability to discriminate between real and pretend acts. Child Development, 77, 1762-1777. doi:10.1111/j.1467-8624.2006. 00972.x

Ma, L., \& Lillard, A. S. (2013). What makes an act a pretense one? Young children's pretend-real judgments and explanations. Child Development Research, 2013. doi:10.1155/2013/467872

Mitchell, R. W. (Ed.). (2002). Pretending and imagination in animal and children. Cambridge: Cambridge University Press.

Mitchell, R. W., \& Clark, H. (2015). Experimenter's pantomimes influence children's use of body part as object and imaginary object pantomimes: A replication. Journal of Cognition and Development, 16, 703-718. doi:10.1080/15248372.2014.926270

Nakamichi, N. (2015). Maternal behavior modifications during pretense and their long-term effects on toddlers' understanding of pretense. Journal of Cognition and Development, 16, 541-558. doi:10.1080/ 15248372.2014 .926271

Nishida, T. K., \& Lillard, A. S. (2007). The informative value of emotional expressions: "Social referencing" in mother-child pretense. Developmental Science, 10, 205-212. doi:10.1111/j.1467-7687. 2007.00581.x

Pederson, D. R., Rook-Green, A., \& Elder, J. L. (1981). The role of action in the development of pretend play in young children. Developmental Psychology, 17, 756-759. doi:10.1037/0012-1649. 17.6.756

Pellis, S. M., Burghardt, G. M., Palagi, E., \& Mangel, M. (2015). Modeling play: Distinguishing between origins and current functions. Adaptive Behavior, 23, 331-339.

Pellis, S. M., \& Pellis, V. C. (2007). Rough-and-tumble play and the development of the social brain. Current Directions in Psychological Science, 16, 95-98.

Pellis, S. M., \& Pellis, V. C. (2009). The playful brain: Venturing to the limits of neuroscience. Oxford: Oneworld.

Pellis, S. M., \& Pellis, V. C. (2016). Play and cognition: The final frontier. In M. Olmstead (Ed.), Animal cognition: Principles, evolution, and development (pp. 201-230). New York: Nova Science Publishers.

Piaget, J. (1962). Play, dreams, and imitation in childhood. New York: Norton. G. Gattegno \& F. M. Hodgson, Trans.

Richert, R. A., \& Lillard, A. S. (2004). Observers' proficiency at identifying pretense acts based on behavioral cues. Cognitive Development, 19, 223-240. doi:10.1016/j.cogdev.2004.01.001

Slade, A. (1987). A longitudinal study of maternal involvement and symbolic play during the toddler period. Child Development, 58, 367375. doi: $10.2307 / 1130513$

Watson, M. W., \& Fischer, K. W. (1977). A developmental sequence of agent use in late infancy. Child Development, 48, 828-836. doi:10. $2307 / 1128331$

Watson, M. W., \& Jackowitz, E. R. (1984). Agents and recipient objects in the development of early symbolic play. Child Development, 55, 1091-1097. doi:10.1111/j.1467-8624.1984.tb03847.x

Youngblade, L. M., \& Dunn, J. (1995). Individual differences in young children's pretend play with mother and sibling: Links to relationships and understanding of other people's feelings and beliefs. Child Development, 66, 1472-1492. doi:10.2307/1131658 